\title{
The pattern of drug use among term neonates and cost implications: Results from a study in a Sri Lankan neonatal care unit.
}

\author{
Gunawardane DA ${ }^{1}$, Dharmaratne $\mathrm{SD}^{2}$, Rowel $\mathrm{DS}^{3}$. \\ key words: neonatal therapeutics, drug utilization, cost of drugs.
}

\section{Abstract}

Background Newborns in neonatal care units are exposed to a considerable number of medications. Although patterns of drug utilization in neonatal care units are changing rapidly, current data on drug utilization patterns in neonatal care units are limited, especially with regard to term neonates.

Objectives The aim of the study was to describe the drug utilization pattern, its associated factors and total drug cost on term neonates admitted to the Neonatal Care Unit (NCU) at Teaching Hospital Kandy (THK).

Methods and materials This study was a secondary analysis of data based on a follow-up study conducted among term neonates delivered at Teaching Hospital Kandy. A total of 175 neonates were studied over a period of 4 months, from February to May 2015.

Results Benzylpenicillin was the most frequently used drug and on average $6.16(+2.99)$ drugs were prescribed per neonate. Only length of stay and sex was associated with average drug use per neonate. Nearly seventy percent of total drug cost to treat term neonates was spent on 2 drugs; gentamicin and surfactant. All the other individual drugs account for a proportion of ten percent or less.

Conclusions Being the drug which is responsible for the heights share of total drug cost, gentamicin should be monitored closely to ensure rational use. Similar studies done in large scale at regular intervals can reflect the changing patterns of drug prescribing, which helps the healthcare planners to develop necessary guidelines and take action to make necessary drugs available.

1. Postdoctoral Research Fellow, School of Public Health, Faculty of Health Sciences, University of Adelaide.

2. Professor in Community Medicine and Consultant Community Physician, Department of Community Medicine, Faculty of Medicine, University of Peradeniya. Sri Lanka.

3. Consultant Community Physician, National Programme Manager, Intranasal and Newborn Care Unit, Family Health Bureau, Ministry of Health, Sri Lanka

https://orcid.org/0000-0001-8844-296X

\section{Introduction}

Newborns in neonatal care units are exposed to a large number of medications. Although patterns of drug utilization in neonatal care units are changing rapidly, current data on drug utilization patterns in neonatal care units are limited, especially with regard to term neonates. ${ }^{1,2}$

Newborn maturity plays a key role in determining the pharmacokinetics of a drug. This is because development factors have an effect on drug absorption, distribution, metabolism and clearance. Mean the number of drug usage is reducing with increasing gestational age as well as increasing birth weight. ${ }^{3}$

Available drug utilization patterns among newborns show that the average number of drugs administrated per neonate in the neonatal intensive care unit had progressively increased over the years. ${ }^{3}$ But when focused on the term gestational age, it varies from place to place; study done in USA(3) during 1997 to 2004, reported mean number of drug use among term neonates as 2.4, where as a study done in Germany, ${ }^{4}$ in 2005 reported mean number of drug use among term neonates as 10 . In most of the studies, antibiotics were the drug category with the highest utilization rate..$^{3-5}$

Furthermore, most of the developing countries have limited funds for health care so it is important to prescribe drugs rationally to get the maximum out of the available resources. In that case, monitoring of drug utilization pattern is important to ensure maximum utilization of purchased drugs and limit the wastage. ${ }^{2}$

Most of the reported drug utilization studies have been carried out in Neonatal Care Units (NCUs) are overrepresented by preterm neonates. ${ }^{1-5}$ So this paper is aim to evaluate the drug utilization pattern, its associated factors and total drug cost on term neonates admitted to neonatal care unit of Teaching Hospital Kandy (THK), Sri Lanka.

\section{Methods}

This study is a secondary analysis of data from a prospective follow-up study conducted among term neonates delivered at THK, to describe the drug utilization pattern and its associated factors. A total of 175 term neonates were studied over a period of 4 months from Feb to May 2015.The study was approved by the ethics review committee of the faculty of medicine Colombo. 
In the follow-up study following term neonates were excluded from the study; neonates of mothers with uncertain Last Menstrual Period (LMP), neonates of mothers who did not have an ultrasound scan (USS) before the completion of 24 weeks of gestation and neonates of mothers whose USS Expected Date of Delivery (EDD) is different from EDD calculated by the LMP more than 14 days. Since there was only one death, it was excluded from the secondary data analysis to maintain uniform survival status for the analysis. During the follow-up study, drugs prescribed to the neonates were extracted from the neonate's Bed Head Ticket. To find out the cost of drugs per each term neonate, the quantity was multiplied by the unit cost. For Drugs, which are provided by the Medical Supplies Division (MSD), the unit cost had assigned according to the annual drug estimates issued by the MSD (2015). For drugs, which are not supplied by the MSD, State Pharmaceuticals Corporation (SPC) price was used as the unit price.

All drugs were coded as per World Health Organization Anatomical Therapeutic Chemical (ATC) classification system, ${ }^{6}$ to describe the utilization pattern according to the organ or system on which they act. Neonatal conditions were classified based on the main neonatal condition according to the ICD 10 classification. ${ }^{7}$

Categorical variables were expressed as counts (Percentages) and continuous variables as mean and median with range. Due to the skewed distribution number of drug according to the newborn characteristics were tested by using Kruskal-Wallis $\mathrm{H}$ nonparametric test. Data were analysed by using Microsoft Access, Excel 2016 versions and SPSS $20^{\text {th }}$ version.

\section{Results}

As shown in Table 01, male neonates $(66.9 \%)$ in the study sample outnumbered the female neonates. Approximately half $(49.2 \%)$ of the term neonates were delivered at early term (37 or 38 weeks of gestation). Twenty-eight percent of neonates had low birth weight. Nearly half $(56.6 \%)$ of the term neonates admitted to $\mathrm{NCU}$ was delivered through caesarean section. When considering the main diagnosis most prevalent neonatal condition was bacterial sepsis $(24.0 \%)$ followed by respiratory distress of newborn (19.4\%).

\section{Table 01 Characteristics of term neonates}

\begin{tabular}{|l|l|l|}
\hline Newborn characteristic & $\begin{array}{l}\text { Number of } \\
\text { newborns }\end{array}$ & Percentage \\
\hline Sex & & \\
\hline Male & 117 & 66.9 \\
\hline Female & 58 & 33.1 \\
\hline Gestational age at birth & & \\
\hline 37 & 43 & 24.6 \\
\hline 38 & 43 & 24.6 \\
\hline 39 & 31 & 17.7 \\
\hline 40 & 56 & 32.0 \\
\hline 41 & 2 & 1.1 \\
\hline Birth weight & & \\
\hline$<2500$ & 49 & 28.0 \\
\hline $2500-4000$ & 121 & 69.1 \\
\hline$>4000$ & 5 & 2.9 \\
\hline Mode of delivery & & \\
\hline NVD & 74 & 42.3 \\
\hline CS & 99 & 56.6 \\
\hline Instrumental & 2 & 1.1 \\
\hline Length of stay & & \\
\hline$<=6$ days & 42 & 24.0 \\
\hline $7-12$ Days & 97 & 55.4 \\
\hline$>12$ days & 63 & 36.0 \\
\hline Main Diagnosis according to ICD 10 classification & & \\
\hline P36- Bacterial sepsis of newborn & 42 & 24.0 \\
\hline & & \\
\hline
\end{tabular}




\begin{tabular}{|l|l|l|}
\hline P22- Respiratory distress of newborn & 34 & 19.4 \\
\hline P59- Neonatal jaundice from other and unspecified causes & 26 & 14.9 \\
\hline P21- Birth asphyxia & 17 & 9.7 \\
\hline P55- Haemolytic disease of fetus and newborn & 15 & 8.6 \\
\hline P5- Slow fetal growth and fetal malnutrition & 8 & 4.5 \\
\hline Z29- Need for other prophylactic measures & 8 & 4.5 \\
\hline P24- Neonatal aspiration syndromes & 7 & 4.0 \\
\hline P70- Transitory disorders of carbohydrate metabolism - newborn & 7 & 4.0 \\
\hline P23- Congenital pneumonia & 5 & 2.9 \\
\hline Q37- Cleft palate with cleft lip & 2 & 1.1 \\
\hline Q3- Congenital hydrocephalus & 1 & 0.6 \\
\hline Q42- Congenital absence, atresia and stenosis of large intestine & 1 & 0.6 \\
\hline Q5- Spina bifida & 1 & 0.6 \\
\hline Z3- Medical observation for suspected diseases and conditions & 1 & 0.6 \\
\hline & 175 & 100.0 \\
\hline
\end{tabular}

Mean drug use was 6.16 (SD 2.99), per neonate and that was varied depending on neonatal characteristics. But, in the nonparametric analysis statistically significant associations were noted only with two factors; length of stay and sex. Based on the birth weight the highest mean drug use was in more than $4000 \mathrm{~g}$ weight category, whereas according to the gestational age higher mean drug use was among 37 week babies. (Table 02)

\section{Table 2 - Factors associated with mean drug use per term neonate}

\begin{tabular}{|c|c|c|c|c|c|c|}
\hline & Mean & Median & Maximum & Minimum & $\mathrm{x} 2$ & $\mathrm{P}$ \\
\hline All newborns & 6.16 & 6 & 22 & 1 & & \\
\hline Sex & & & & & 7.31 & 0.007 \\
\hline Male & 6.62 & 6 & 22 & 1 & & \\
\hline Female & 5.24 & 5 & 12 & 1 & & \\
\hline Gestational age (Weeks) & & & & & 0.205 & 0.932 \\
\hline 37 & 6.37 & 6 & 13 & 1 & & \\
\hline 38 & 6.16 & 6 & 17 & 1 & & \\
\hline 39 & 6.35 & 6 & 22 & 2 & & \\
\hline 40 & 5.91 & 6 & 14 & 1 & & \\
\hline 41 & 5.5 & 6 & 6 & 5 & & \\
\hline Birth Weight (g) & & & & & 3.169 & 0.205 \\
\hline$<2500$ & 6.33 & 6 & 14 & 3 & & \\
\hline 2500-3999 & 5.95 & 6 & 17 & 1 & & \\
\hline$>4000$ & 9.60 & 6 & 22 & 5 & & \\
\hline Mode of delivery & & & & & 0.88 & .644 \\
\hline Normal vaginal delivery & 5.84 & 6 & 13 & 1 & & \\
\hline Caesarean section & 6.41 & 6 & 22 & 1 & & \\
\hline Instrumental (Vacuum/ forceps) & 5.5 & 6 & 6 & 5 & & \\
\hline \multicolumn{7}{|l|}{ Length of stay (Days) } \\
\hline$<=6$ & 5.14 & 5 & 13 & 1 & 24.78 & 0.000 \\
\hline $6-12$ & 5.58 & 6 & 12 & 1 & & \\
\hline$>12$ & 8.92 & 10 & 22 & 2 & & \\
\hline
\end{tabular}


In total 38 drugs were used on tern neonates. Most frequently used (10 percent or above) drugs were listed in table 03. The anti-infective, benzylpenicillin and

gentamicin were the most widely used drugs followed by calcium gluconate and potassium chloride.

Table 03- Most frequently used drugs*

\begin{tabular}{|l|l|l|l|}
\hline & Drug & $\begin{array}{l}\text { Number of } \\
\text { newborns }\end{array}$ & Percentage \\
\hline 1 & $\begin{array}{l}\text { Benzyl penicillin } \\
\text { Injection 1 million unit } \\
\text { vial (600mg) }\end{array}$ & 169 & $96.6 \%$ \\
\hline 2 & $\begin{array}{l}\text { Gentamicin Sulphate } \\
\text { Injection(20mg/2ml) }\end{array}$ & 133 & $76.0 \%$ \\
\hline 3 & $\begin{array}{l}\text { Calcium gluconate } \\
\text { injection }\end{array}$ & 131 & $74.9 \%$ \\
\hline 4 & $\begin{array}{l}\text { Potassium chloride } \\
\text { Injection }\end{array}$ & 131 & $74.9 \%$ \\
\hline 5 & Dobutamine Injection & 36 & $20.6 \%$ \\
\hline 6 & Amikacin Injection & 32 & $18.3 \%$ \\
\hline 7 & Cefotaxime Injection & 30 & $17.1 \%$ \\
\hline 8 & $\begin{array}{l}\text { Morphine sulphate } \\
\text { injection }\end{array}$ & 19 & $10.9 \%$ \\
\hline & $\begin{array}{l}\text { Total number of } \\
\text { newborns }\end{array}$ & 175 & \\
\hline$*$ Drugs used on more than 10 percent of newborn , except \\
forintravenous fluid
\end{tabular}

According to the ATC calcification system, anti-infectives for systematic use (96.6\%) and drugs for the blood and blood-forming organs (82.8\%) have been prescribed most often, followed by drugs for alimentary tract and metabolism (74.8\%). (Table 04)
As the major group of drug prescribed on term neonates admitted to NCU, the pattern of anti-infective use was further analysed. Majority of newborns have exposed to the benzylpenicillin and gentamicin combination (56.0\%)followed by benzylpenicillin and amikacin (15.4\%) combination and benzylpenicillin, gentamicin and cefotaxime combination (10.9\%). None of them was treated with monotherapy (Fig- 01).

\section{Fig-01 Antibiotic prescribing pattern}

When considering the total drug cost gentamicin is responsible for the greatest share of total drug cost followed by the surfactant. These two drugs shared $70 \%$ of the total drug cost on term neonates admitted to NCU. All the other individual drugs account for a proportion of ten percent or less. (Table 05)

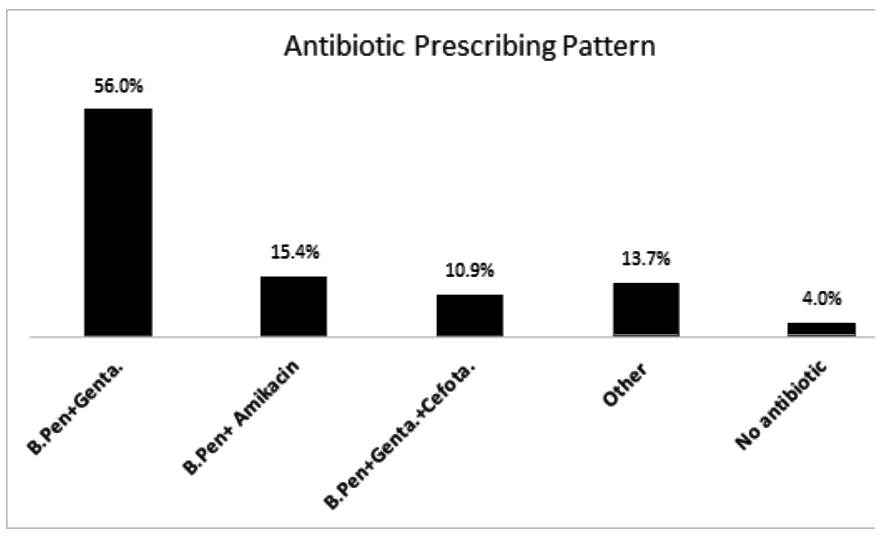

Table 04 - Exposure rates (in percentage) for anatomical levels of the Anatomical Therapeutic Chemical (ACT) classification by gestational age

\begin{tabular}{|l|l|l|}
\hline ATC Classification & $\begin{array}{l}\text { Number of } \\
\text { newborns }\end{array}$ & Percentage \\
\hline A: Alimentary tract and metabolism & 131 & 74.9 \\
\hline B: Blood and blood-forming organs & 145 & 82.9 \\
\hline C: Cardiovascular system & 35 & 20.0 \\
\hline $\begin{array}{l}\text { H: Systemic hormonal preparations, excluding reproductive hormones and } \\
\text { insulins }\end{array}$ & 2 & 1.1 \\
\hline J: Anti-infective for systemic use & 169 & 96.6 \\
\hline M: Musculoskeletal system & 9 & 5.1 \\
\hline N: Nervous system & 24 & 13.7 \\
\hline R: Respiratory system & 7 & 4.0 \\
\hline V: Various ATC structures & 1 & 0.6 \\
\hline Total number of newborns & 175 & \\
\hline
\end{tabular}


Table 05 - Breakdown of drug cost for term neonates

\begin{tabular}{|c|c|c|c|c|}
\hline Drug Name & $\begin{array}{l}\text { Unit Price } \\
\text { (LKR)* }\end{array}$ & $\begin{array}{l}\text { No of } \\
\text { units } \\
\text { used }\end{array}$ & Cost (LKR) & $\%$ \\
\hline Gentamicin Sulphate Injection $(20 \mathrm{mg} / 2 \mathrm{ml})$ & 505.58 & 672 & 339749.76 & 38.4 \\
\hline Surfactant & 25909.0 & 11 & 284999.00 & 32.2 \\
\hline Human immunoglobulin for intravenous use $1 \mathrm{~g}$ Vial & 8002.90 & 10 & 80029.00 & 9.0 \\
\hline $\begin{array}{l}\text { Sodium chloride } 0.18 \% \text { \& Dextrose } 10 \% \text { for intravenous } \\
\text { infusion }\end{array}$ & 86.32 & 352 & 30384.64 & 3.4 \\
\hline Linezolid Injection $600 \mathrm{mg} / 300 \mathrm{ml}$ & 7500.00 & 3 & 22500.00 & 2.5 \\
\hline Calcium gluconate injection & 53.76 & 355 & 19084.80 & 2.1 \\
\hline Atracurium(IV) & 56.70 & 312 & 17690.40 & 2.0 \\
\hline Morphine sulphate injection & 698.53 & 20 & 13970.60 & 1.6 \\
\hline Benzyl penicillin Injection 1 million unit vial (600mg) & 8.87 & 1247 & 11060.89 & 1.2 \\
\hline Albumin Solution (human) & 3147.02 & 3 & 9441.06 & 1.1 \\
\hline Other & & & 56196.31 & 6.3 \\
\hline Total cost & & & 885106.46 & 100 \\
\hline *Based year 2015 & & & & \\
\hline
\end{tabular}

\section{Discussion}

Present study gave us the overall pattern of drug use in a tertiary care NCU in Sri Lanka and reflects the main neonatal conditions for which term neonates were admitted to the unit.

This type of drug utilization studies not only guides for the rational use of drugs making treatment beneficial to patients and also ensures efficient use of available funds by minimizing wastage due to purchasing of drugs which are hardly used.

Demographic profile shows male (66.9\%), predominance in term neonates admitted to NCU, which is consistent with other studies done in similar settings. ${ }^{3,5,6}$ Neonatal sepsis was the most common neonatal condition observed in our study, followed by respiratory distress of newborn as did in most of the other published work. ${ }^{1,4,5}$

In this study, the average number of drugs used per term neonate was $6.16( \pm 2.99)$, which is less than that number reported by Neubert et al, ${ }^{4}$ for term neonates $(10+8.5)$. Drug utilization studies in NCUs in other countries have revealed that anti-infective is the commonest group of drugs prescribed in the NCU., $3-5,8$ This fits well with the findings of our analysis.

In Warrier et $\mathrm{al}^{3}$ study, ampicillin was the most frequently used anti-infective agent among term neonates followed by cefotaxime. Whereas in our study it was benzylpenicillin followed by gentamicin, which is compatible the recommendations given in the newborn care guidelines of $\mathrm{MOH}$ Sri Lanka ${ }^{9}$, Even though guideline allows the use of ampicillin in place of benzyl penicillin. Interestingly, most of similar studies done in NCUs reported the use of ampicillin instead of benzyl penicillin. Due to the same reason, the combinations of antibiotics used in our setting was different from other settings. ${ }^{1-3,8}$ When considering the cost, both ampicillin and benzylpenicillin have more or less similar costs based on the unit prices.

When considering the anatomical levels of drugs used among term neonates, anti-infectives for systematic use and drugs for the blood and blood-forming organs were prescribed mostly compared to the other groups. This is in accordance with the findings of the study conducted by Neubert et al. ${ }^{4}$

Interestingly nearly eighty percent (79.6\%) of total drug cost to treat term neonates were spent on 3 drugs; namely gentamicin, surfactant and human immunoglobulin. Being the drug which is responsible for the highest share of total drug cost, due to the relatively high unit price of paediatric preparation and high frequency of use, gentamicin should be monitored closely to ensure rational use.

If the adult formula of gentamicin $80 \mathrm{mg} / 2 \mathrm{ml}$ ampoule (unit price LKR 7.92) was used, its total cost would be only LKR 5322.24. Even though it is a common practice, it cannot be recommended to use adult formulae instead of paediatric formulae (when it is available) as a cost saving measure, due to the higher chance of administrative errors especially in settings like NCUs. ${ }^{10,11}$ According to the 
MSD national drug estimate report on pharmaceutical items ${ }^{12}$ the annual requirement of paediatric formula of gentamicin sulphate Injection $(20 \mathrm{mg} / 2 \mathrm{ml})$ was 36,215 units in the year 2016. As the most costly drug (based on the unit price) used in the setting, $\mathrm{MOH}$ Sri Lanka, issued a circular to ensure rational use of surfactant. ${ }^{13}$

Unfortunately, it was not possible to comment on the rational use of gentamicin based on the present study findings. But close monitoring of gentamicin use will help to reduce the cost by avoiding any inappropriate use if there is any. So, further studies, based on the individual case scenarios, which take appropriate use of gentamicin into account, will need to be undertaken, to explore, whether there is an inappropriate use of gentamicin in this setting and possibility of replacing gentamicin with a cheaper alternative in selected clinical situations. findings of this study we think will add to the knowledge cost of drugs they frequently used in NCU setting. This awareness will have an impact on the appropriate use of limited resources as found in other studies. ${ }^{14}$

\section{Conclusion}

Benzylpenicillin was the most frequently used drug and on average $6.16(+2.99)$ drugs were prescribed per term neonate admitted to NCU in TH Kandy. Nearly eighty percent of total drug cost to treat term neonates was spent on 3 drugs. Being the drug which is responsible for the heights share of total drug cost, gentamicin should be monitored closely to ensure rational use. Similar studies done in large scale at regular intervals can reflect the changing patterns of drug prescribing, which helps the healthcare planners to develop necessary guidelines and take action to make necessary drugs available.

\section{References}

1. Patel Brijal S, KubavatAmita R, Sondarva Divyesh B, Piparva Kiran G. Drug utilization study in neonatal intensive care unit at tertiary care hospital, Rajkot, Gujarat: a prospective study. World Journal of Pharmacy and Pharmaceutical Sciences. 2015;4(7):2034-42.

2. Hsieh EM, Hornik $C P$, Clark RH, Laughon $M M$, Benjamin DK, Smith PB. Medication use in the neonatal intensive care unit. American journal of perinatology. 2014;31(09):811-22.

3. Warrier I, Du W, Natarajan G, Salari V, Aranda J. Patterns of drug utilization in a neonatal intensive care unit. The Journal of Clinical Pharmacology. 2006;46(4):449-55.
4. Neubert A, Lukas K, Leis T, Dormann H, Brune K, Rascher W. Drug utilisation on a preterm and neonatal intensive care unit in Germany: a prospective, cohort-based analysis. European journal of clinical pharmacology. 2010;66(1):87.

5. Kishanrao Choure M, Ramratan Jadhav R, Laxmanrao Padwal S. Drug utilization study in neonatal intensive care unit at rural tertiary care hospital 2017. 102 p.

6. WHO Collaborating Centre for Drug Statistics Methodology, Guidelines for ATC classification and DDD assignment 2013. Oslo, 2012.

7. WHO. Classifications: World Health Organization; 2017 [cited 2017]. Available from: http://www.who. int/classifications/icd/en/.

8. Chatterjee S, Mandal A, Lyle N, Mukherjee S, Singh AK. Drug utilization study in a neonatology unit of a tertiary care hospital in eastern India. Pharmacoepidemiology and drug safety. 2007;16(10):1141-5.

9. National Newborn Care Guidlines. Neonatal sepsis and antibiotic therapy in newborns: Ministry of Health, Sri Lanka; 2013. p. 51-69.

10. World Health Organization. Promoting safety of medicines for children: World Health Organization; 2007.

11. Cohen MR. Medication errors: causes, prevention, and risk management: Jones \& Bartlett Learning; 1999.

12. Medical Supplies Division. National drug estimate report - Pharmaceutical Items. Sri Lanka: MSD, Division MS; 2016.

13. Guidelines for surfactant use, Pub. L. No. General Circular No; 01-19/ 2011 Stat. Ministry of Health Sri Lanka (2011).

14. Geoghegan AR, Moore S, O'Donnell CP. Doctors' perceptions of the cost of consumable items used in neonatal intensive care. Acta Paediatr. 2015;104(11):e473. doi: 10.1111/apa.13145. PubMed PMID: 26237176. 